\title{
Colonia Caesar Augusta: el impacto sobre el territorio y las comunidades indígenas*
}

Francisco Beltrán Lloris

\section{Universidad de Zaragoza}

fbeltran@unizar.es

\section{Fecha recepción 22.02.2016 / Fecha aceptación 05.05.2016}

\section{Resumen}

Estudio sobre la conformación de la extensa pertica de colonia Caesar Augusta, constituida por los territorios de varias ciuitates precedentes, $\mathrm{y}$ de las condiciones en las que pudieron ser integradas en la colonia las poblaciones locales en él asentadas.

\section{Palabras clave}

Caesar Augusta, territorio, incolae.

\section{Abstract}

This paper presents a study on the formation of the large pertica attributed to colonia Caesar Augusta (comprising the territories of several earlier civitates) and on the conditions under which the local populations could be integrated into the colony.

Key words:

Caesar Augusta, territory, incolae.

\footnotetext{
* Este trabajo ha sido realizado dentro del marco del proyecto "El nacimiento de las culturas epigráficas en el Occidente mediterráneo (II-I a. E.)”, FFI2012-36069-C03-03.
} 


\section{La «colonia de Augusto», un núcleo de vertebración regional}

Pese a su estratégica situación geográfica, en el centro de una red de caminos naturales que facilita el acceso hacia el Mediterráneo, la Meseta, el Noroeste y los Pirineos, sólo a comienzos del siglo I a. E. aparecen los primeros indicios de que la comarca zaragozana había empezado a desempeñar un cierto papel en la vertebración de la región y ello, por iniciativa romana ${ }^{1}$. Se trata, en concreto, de dos medidas adoptadas por el gobernador C. Valerio Flaco que seleccionó a la ibérica Salduie (Zaragoza) como centro de reclutamiento ${ }^{2}$ y a su vecina meridional celtibérica, Contrebia Belaisca (Botorrita), como probable sede de su tribunal itinerante ${ }^{3}$. No obstante este papel no se consolidó todavía: en los años 40 a. E. fue una ciudad ibérica situada $50 \mathrm{~km}$ hacia el este y en la ribera izquierda del Ebro, Celsa (Velilla de Ebro), ${ }_{4}^{4}$ la elegida por César para establecer la primera colonia romana del interior, en una ubicación que se explica más como punto avanzado de la penetración romana

1. Al respecto F. Beltrán, "Introducción" en ID., (Ed.), Colonia Caesar Augusta, Roma, 2007, 3-13, cit. p. 4, con bibliografía. Vid. en esta misma obra un estado de la cuestión y una amplia síntesis, fundamentalmente arqueológica, sobre la Zaragoza romana.

2. En concreto de la turma Salluitana, mencionada en el bronce de Ascoli del año 89 a. E., CIL I2 709: F. Pina, “¿Por qué fue reclutada la Turma Salluitana en Salduie?”, en Gerión, vol. 21, 2003, 197-204; F. Beltrán, "El valle medio del Ebro durante el período republicano: de limes a conuentus" en G. Cruz Andreotti, P. Le Roux y P. Moret (Eds.), La invención de una geografía de la Península Ibérica. I. La época republicana, Málaga - Madrid, 2006, 217-240.

3. Según parece desprenderse de la tabula Contrebiensis del año 87 a. E., CIL I 3951a: F. Beltrán, "Vltra eos palos. Una nueva lectura de la línea 7 de la Tabula Contrebiensis", en Espacios, usos y formas de la epigrafía hispana en épocas antigua y tardoantigua. Homenaje al Dr. Armin U. Stylow, Anejos de AEspA, vol. 48, Mérida 2009, 33-42, cit. p. 40-41.

4. Una síntesis sobre la ciudad en M. Beltrán, Celsa, Zaragoza, 1991 y Colonia Celsa. Velilla de Ebro, Madrid 1997 con la bibliografía fundamental. 
desde la costa que como centro vertebrador de la región, como, de hecho, su temprano abandono a partir de c. 60 d. E. parece demostrar ${ }^{5}$.

Fue Augusto quien, tras el final de la conquista del noroeste peninsular, seguramente hacia 15 o 14 a. E., ${ }^{6}$ tomó la decisión de emplazar en la actual Zaragoza el centro destinado a articular una extensa región en torno al valle medio del Ebro. Como no podía ser de otra forma, la ciudad fue concebida como colonia romana, el más prestigioso rango del que una ciudad provincial podía disfrutar. Significativamente, el emperador le concedió el singular privilegio - único en todo el Imperio- de ostentar su mismo nombre, colonia Caesar Augusta, acuñado obviamente sobre el del príncipe: Imperator Caesar Augustus ${ }^{7}$. Para desempeñar esta función la ubicación de la actual Zaragoza era idónea. A su estratégica situación en la red natural de comunicaciones, se unían otros dos factores que potenciaban su capacidad integradora: se encontraba, por una parte, en el punto exacto de confluencia de los tres principales ámbitos culturales y lingüísticos del nordeste -ibérico, celtibérico y vascónico-, representados en la comarca por Salduie, Contrebia Belaisca y Alauo (Alagón), y, por otra, ocupaba el centro de la elipse delineada por las principales ciudades promocionadas por César y el propio Augusto en la región ${ }^{8}$ la colonia romana de Celsa y los municipios - romanos o latinos- de Ilerda (Lérida), Osca (Huesca), Cascantum (Cascante), Graccurris (Alfaro), Calagurris (Calahorra), Turiaso (Tarazona), Bilbilis (Calatayud), Leonica (?) y Osicerda (La Puebla de Híjar / Alcañiz) ${ }^{9}$. Para reforzar este papel, Augusto reestructuró la red viaria que pasó de estar concebida como un vector de penetración desde el litoral mediterráneo a través del corredor situado entre los Pirineos y el Ebro a adoptar una disposición radial con Caesar Augusta en el centro ${ }^{10}$.

5. Al respecto, F. Beltrán en F. Beltrán, M. Martín-Bueno y F. Pina, Roma en la cuenca media del Ebro, Zaragoza, 2000, 59-62.

6. Una síntesis sobre la fecha de fundación en Beltrán, op. cit., 2007, 5-6 y más pormenorizadamente F. Beltrán, "Le territoire de Colonia Caesar Augusta (Saragosse) et ses premiers habitants", en L. Callegarin y F. Rechin (Eds.), Espaces et societés à l'époque romaine: entre Garonne et Èbre. Hommages à Georges Fabre, Pau, 2009, 55-67, cit. p. 58-60.

7. Sobre la excepcionalidad del nombre de la colonia, F. Beltrán, "Caesar Augusta, ciudad de Augusto", Caesaraugusta, vol. 69, 1992, 31-44; Beltrán en Beltrán, Martín-Bueno y Pina, op. cit., 2000, 77-78; ID., op. cit., 2007, 4-9, en donde se vincula la imposición de este nombre no sólo al importante papel atribuido a la colonia en la vertebración del territorio, sino también a la existencia de una notoria concentración en la región de ciudades denominadas a partir de prohombres republicanos: Gracchurris, Pompelo y Lepida / Celsa; un punto de vista diferente, aunque no excluyente, sugiere G. Fatás que lo explica por haber sido fundada la colonia en el quincuagésimo aniversario de Augusto, M. Beltrán y G. Fatás, Caesar Augusta, ciudad romana, Zaragoza, 1998, 8. Ver ahora, F. Beltrán, “Colonia Caesar Augusta. Reflexiones sobre el nombre romano de Zaragoza”, en A. Duplá, M. V. Escribano, L. Sancho y M. A. Villacampa (Eds.), Miscelánea de estudios en homenaje a Guillermo Fatás Cabeza, Zaragoza, 2014, 129-139.

8. Plin. NH 3.24.

9. Beltrán en Beltrán, Martín-Bueno y Pina, op. cit., 2000, 81.

10. Beltrán, op. cit., 2006; F. Beltrán y M. Á. Magallón, “El territorio”, en Beltrán (Ed.) op. cit., 2007, 104 ss.; sobre la red viaria: M. Á. Magallón, La red viaria romana en Aragón, Zaragoza 1997. 
Como lógico corolario de todo ello, Caesar Augusta fue convertida, además, en sede de un extenso convento jurídico al que dio nombre ${ }^{11}$. Como sede conventual, la ciudad actuaba como espacio privilegiado de las relaciones entre la administración provincial y las comunidades de la región, pero también de negociación y comunicación entre las elites urbanas de las ciudades agrupadas en el convento. Allí habrían de celebrarse asambleas anuales para discutir asuntos comunes pero también para expresar la lealtad al príncipe a través del culto imperial, que encabezaba el flamen conventual, elegido por los representantes de las ciudades en tal ocasión y su portavoz en los concilia provinciales anuales de la capital, Tarraco ${ }^{12}$. De esta manera, Caesar Augusta se convertía en un instrumento para dotar de coherencia y personalidad a un espacio culturalmente heterogéneo e integrado por ciudades con diferentes niveles de promoción política - romanas, latinas, peregrinas-, que, además, a escala provincial, servía de transición y sutura, por una parte, entre el litoral y el valle del Ebro, que concentraban la totalidad de las ciudades privilegiadas de la Hispania Citerior - menos de 50 sobre un total de $293-,{ }^{13}$ y, por otra, con las áreas más occidentales, en parte recientemente sometidas y desprovistas por completo de ellas. La región abarcaba la vieja frontera republicana entre las regiones ibéricas, más tempranamente conquistadas y pacificadas desde comienzos del siglo II a. E., y las célticas, sometidas lentamente en el curso de esa centuria. Así, Caesar Augusta y su entorno marcaban en este punto de la provincia el límite occidental de la Hispania más integrada políticamente como, en otras áreas peninsulares, lo hacían las también colonias de Libisosa (Lezuza) o Scallabis (Santarem) y, sobre todo, Emerita Augusta (Mérida), una ciudad que, junto a dos previas fundaciones coloniales, Norba (Cáceres) y Metellinum (Medellín), en buena medida eclipsadas por ella — como Celsa lo fue por Caesar Augusta—, desempeñó sobre el Guadiana una función muy similar a la cesaraugustana en el valle del Ebro ${ }^{14}$.

Para que la nueva fundación pudiera desempeñar este papel vertebrador Augusto $-\mathrm{y}$ sus sucesores - no escatimaron medios. La adquisición de las tierras que debían conformar su extensísimo territorio pudo ser incautada o sufragada por el príncipe con una parte de esos 260 millones de sestercios que, según su propio testimonio, invirtió en 30 y 14 a. E. para comprar bienes raíces provinciales ${ }^{15}$. Asentó allí a un contingente de veteranos legionarios de la IV Macedónica, la VI Victoriosa y la X Gemela,${ }^{16}$ en torno a unos tres millares posiblemen-

11.Además del clásico trabajo de L. Sancho, El convento jurídico caesaraugustano, Zaragoza, 1981, véase más recientemente P. Ozcáriz, Los conventos de la Hispania Citerior, Madrid, 2006.

12. F. Beltrán y J. Velaza, "El límite occidental del convento jurídico cesaraugustano”, en J. Andreu (Ed.), Entre Vascones y Romanos: sobre las tierras de Navarra en la Antigüedad, en Cuadernos de Arqueología de la Universidad de Navarra, vol. 21, 2013, 51-71, cit. pp. 52-58.

13. Plin. NH 3.18.

14. Sobre Emerita véase la síntesis de X. Dupré (Ed.), Colonia Augusta Emerita, Roma, 2004.

15. RGDA 16.

16. Según atestiguan las acuñaciones monetales locales: A. Burnett, M. Amandry y P. P. Ripollès, Roman provincial coinage. I (= RPC), London-Paris 1992, núms. 319, 325, 326, 346. 
$t^{17}$. Estos eran representantes escogidos de esa columna vertebral del cuerpo cívico romano que era el ejército, según correspondía a una ciudad que en tanto que colonia debía actuar como effigies paruae simulacraque del pueblo romano, por decirlo con palabras de Aulo Gelio (Noct. Att. 16.13.9), y como el prestigioso espejo de romanidad en el que habían de mirarse las comunidades de la región. La distinguió - como a otras de sus colonias- con el importante privilegio económico de la immunitas fiscal (Plin. NH 3.24). Contribuyó a la construcción del primer núcleo urbano y a dotarlo de una monumentalidad acorde con su función ${ }^{18}$, incluido un gran foro, situado al este de la actual plaza del Pilar, que, con sus instalaciones anejas, cubría un área de más de 170 x 160 m, en torno a una plaza de 103 x 54 m articulada sobre un templo probablemente dedicado al culto imperial ${ }^{19}$, y que resultaba idóneo para satisfacer las necesidades no sólo de la colonia sino del convento jurídico. Propulsó la puesta en marcha de infraestructuras fundamentales para la ciudad como las viarias, ya mencionadas, pero también de las hidráulicas destinadas sobre todo a la irrigación, que habrían de desempeñar un papel fundamental en la economía de la ciudad, aportando para todo ello financiación y mano de obra según se desprende de las referencias a las legiones IV Macedónica, VI Victoriosa y X Gemela grabadas sobre diversos sillares del foro de la ciudad así como sobre varios miliarios de la calzada a Pompelo ${ }^{20}$. La domus Augusta siguió distinguiendo con su predilección a la ciudad durante muchos años como se deduce del hecho de que hasta cuatro príncipes julio-claudios aceptaran desempeñar magistraturas locales en la colonia: Germánico en época de Augusto así como Druso y Nerón Césares y Calígula en época de Tiberio ${ }^{21}$, todos ellos duunviros honoríficos, que pudieron contribuir también a la conformación del núcleo urbano y a su ornamentación en sus primeros decenios de existencia.

17. No hay datos específicos al respecto, pero recuérdese, por ejemplo, que según Estrabón (4.6.7) los veteranos asentados por Augusto en Augusta Praetoria fueron tres mil, el mismo número que en Cartago (App. Pun. 136).

18. Sobre el urbanismo en época augústea y julio-claudia, vid. M. Beltrán, “Topografía y evolución urbana”, en Beltrán (Ed.), op. cit. 2007, 30-36: en esta fase se eleva —o al menos se diseña- la muralla y se traza el tendido viario, se acomete el saneamiento de la ribera, el primer foro, un macellum, el sistema de alcantarillado (sobre el cual ver ahora, F. Escudero y M. P. Galve, Las cloacas de Caesaraugusta y elementos de urbanismo y topografía de la ciudad antigua, Zaragoza, 2013), el gran foro, el puerto fluvial, las termas de San Juan y San Pedro, un nuevo mercado, el teatro,...

19. F. Escudero, J. A. Hernández Vera y J. Núñez, “Arquitectura oficial”, en Beltrán (Ed.), op. cit., 2007, 43-56, cit. pp. 54-56.

20. Las marcas del foro en F. Beltrán, "Marcas legionarias de la VI Victrix y la X Gemina en el foro de Caesar Augusta”, en Veleia 24-25, 2007-2008, Homenaje a Ignacio Barandiarán Maestu, 1069-1079. Sobre los miliarios: J. Lostal, Los miliarios de la provincia tarraconense (conventos tarraconense, cesaraugustano, cluniense y cartaginense), Institución Fernando el católico, Zaragoza 1992, núms. 18-20; y sobre la vía: M. C. Aguarod y J. Lostal, “La vía romana de las Cinco Villas”, en Caesaraugusta, vol. 55-56, 1982, 167-218. Es insegura la atribución a la legio IIII de las marcas descubiertas recientemente en diversos sillares de la presa de Muel por P. Uribe et alii, "La presa romana de Muel: novedades de hidráulica romana en el valle medio del Ebro”, en L. G. Lagóstena, J. L. Cañizar y L. Pons (Eds.), Aquam perducendam curavit. Captación, uso y administración del agua en las ciudades de la Bética y del occidente romano, Cádiz, 2010, 333-345.

21. RPC núms. 325-329; 342-343; 362-364 
Cualquiera de estos aspectos merecería profundización desde la perspectiva de estudio que persigue este coloquio, sin embargo los organizadores del mismo han sugerido para esta contribución un enfoque dirigido preferentemente hacia el impacto entre las poblaciones indígenas de la fundación de la colonia, una cuestión que, por desgracia, resulta extremadamente difícil de afrontar directamente con los datos disponibles, pero sobre la que se pueden avanzar algunas reflexiones e hipótesis a través del estudio del territorio, al que dedicaremos las próximas páginas.

\section{La pertica cesaraugustana, un territorio enorme y previamente desestructurado (fig. 1)}

La situación en la que se encontraba la región del Ebro medio es un aspecto que hasta la fecha no ha sido suficientemente valorada en relación con la fundación de Caesar Augusta. A fines del período republicano la red urbana del entorno regional zaragozano mostraba crudamente los destructivos efectos provocados en ella por las guerras civiles del siglo I a. E. ${ }^{22}$ Muchos de los asentamientos más importantes de la zona, destruidos a comienzos del siglo I a. E., no habían vuelto a recuperar su rango urbano: así ocurría con las ciudades de La Cabañeta (El Burgo de Ebro) y La Corona (Fuentes de Ebro), caracterizadas, sobre todo la primera, por la marcada presencia de población itálica ${ }^{23}$; con los yacimientos ibéricos de Los Castellazos (Mediana de Aragón) ${ }^{24}$ y del Cabezo de Alcalá (Azaila) ${ }^{25}$ así como con los celtibéricos de El Piquete de la Atalaya (Azuara) - identificado tentativamente con la ceca de belikio-,${ }^{26}$ de Contrebia Belaisca (Cabezo de las Minas, Botorrita) ${ }^{27}$ y de La Tijera (Urrea de Jalón) ${ }^{28}$.

22. Sobre las guerras sertorianas en la región puede verse la síntesis de F. Pina en Beltrán, Martín-Bueno y Pina, op. cit., 2000, 31-36 y M. Beltrán, "La etapa de Sertorio en el valle medio del Ebro. Bases arqueológicas", en Pallas 60, 2002, 45-92; para las diferentes ciudades constituye una útil guía el estudio de J. Á. Asensio, La ciudad en el mundo prerromano en Aragón, Zaragoza, 1995.

23. Asensio, op. cit., 1995, 142 ss. y 235 ss.; A. Ferreruela y J. A. Mínguez, "Dos modelos de implantación urbana romanorrepublicana en el valle medio del Ebro: las ciudades de La Cabañeta y La Corona”, en AEspA, no 76, 2003, 247-262; sobre La Cabañeta y los materiales itálicos, J. A. Mínguez y B. Díaz, "Grafitos sobre cerámica -ibéricos, latinos, griegos y signos- procedentes del yacimiento romanorrepublicanao de La Cabañeta (El Burgo de Ebro, Zaragoza)", en AEspA, no 84, 2011, 53-88.

24. Asensio, op. cit., 1995 (cit. nota 23), 216 ss.

25. Asensio op. cit., 1995, 146 ss.; entre las últimas contribuciones de M. Beltrán, véase Azaila, nuevas aportaciones deducidas de la documentación inédita de Juan Cabré Aguiló, Institución Fernando el Católico, Zaragoza, 1995.

26. Asensio op. cit., 1995, 272 ss.

27. Asensio op. cit., 1995, 168 ss.; más bien confusa resulta la síntesis arqueológica presentada por M. Medrano y M. A. Díaz en F. Villar et alii, El IV bronce de Botorrita (Contrebia Belaisca): arqueología y lingüística, Universidad de Salamanca, Salamanca 2001, 13-38.

28. Asensio op. cit., 1995, 294 ss. 


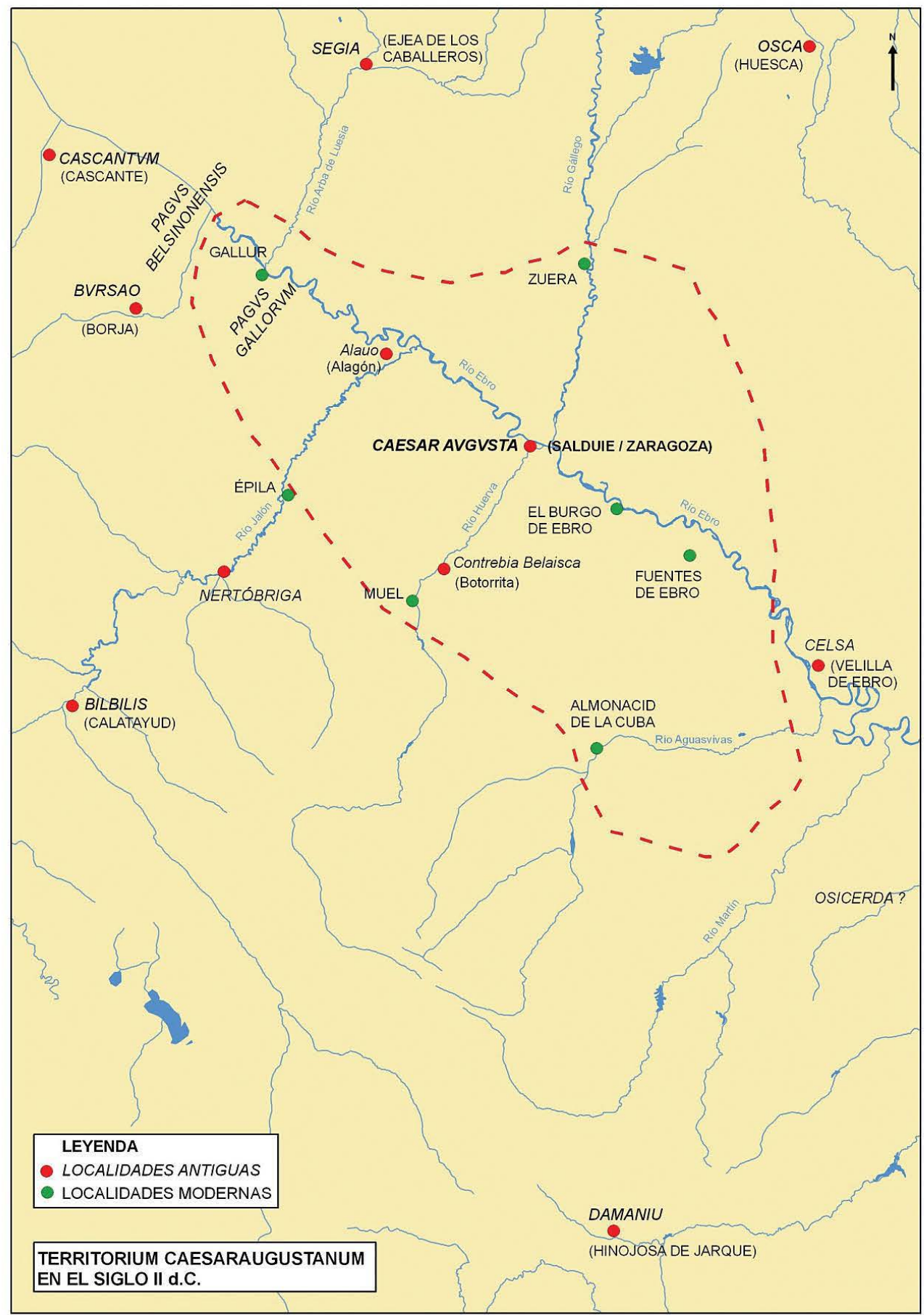

Figura 1. Reconstrucción del territorio cesaraugustano (elaborada para F. Beltrán: «El territorium Caesaraugustanum», en I. Aguilera y J. L. Ona (Eds.), Delimitación comarcal de Zaragoza. Territorio 36, Zaragoza 2011). 
No hay datos, a cambio, respecto de la vascónica Alauo ${ }^{29}$ y de la propia Salduie, ibéri$\mathrm{Ca}^{30}$, en el primer caso por no haber sido identificado con seguridad su emplazamiento, sin duda en Alagón o sus proximidades, y en el segundo por la superposición del núcleo urbano de Caesar Augusta. Algunos de ellos, como Contrebia Belaisca, se repoblaron en época imperial y otros surgieron en este momento, caso de Nuestra Señora del Pueyo (Belchite) ${ }^{31}$ y quizá del uicus central del pagus Gallorum, en El Razazol (Gallur) ${ }^{32}$, pero sin alcanzar en ningún caso rango urbano.

Más allá de esta amplia zona sí tenemos constancia de la persistencia de núcleos urbanos plenamente vigentes, en muchos casos privilegiados por César y Augusto, caso de la colonia Celsa o de los municipios romanos de Osca, Turiaso y Bilbilis, y el latino de Osicerda, y en otros, de rango peregrino como Segia (Ejea de los Caballeros) y Bursao (Borja), mientras que el importante asentamiento de Belsino (El Convento, Mallén) debía formar parte del territorio del municipio latino de Cascantum, según ha revelado la Lex riui Hiberiensis ${ }^{33}$.

Evidentemente, tal estado de cosas - no suficientemente destacado hasta el momento- supone una profunda desestructuración del territorio, aunque no implica desde luego su despoblamiento: más allá de la posible persistencia de Alauo y Salduie, cabe suponer la permanencia de grupos de agricultores en establecimientos rurales y la subsistencia en todas esas ciudades o en su entorno de una población más o menos residual, aunque la carencia de estudios sobre el territorio rural — que por cierto serían muy bienvenidos-impida hacerse una idea precisa de la situación del poblamiento ${ }^{34}$. Los habitantes de este territorio,

29. Asensio op. cit., 1995, 131 ss.

30. Asensio op. cit., 1995, 318 ss.; sobre los materiales ibéricos recuperados en el centro de Zaragoza, fundamentalmente entre la plaza de La Seo y la calle Universidad, I. Aguilera, "Salduie", en Zaragoza. Prehistoria y Arqueología, Ayuntamiento de Zaragoza, Zaragoza 1991, 13-15, incluyendo el importante lienzo de muro de $34 \mathrm{~m}$. de longitud localizado en la calle Sepulcro 1-15, que podría corresponder a las defensas de la ciudad ibérica; el espacio mejor conocido corresponde a unas estructuras domésticas de corte itálico, cuyo nivel de abandono (C2) se fecha mediados del siglo I a. E.: M. P. Galve, Los antecedentes de Caesaraugusta. Estructuras domésticas de Salduie, Zaragoza 1996; G. Fatás y M. Beltrán, Salduie, ciudad ibérica, Zaragoza, 1997, 117.

31. Asensio, op. cit., 1995, p. 327 ss.

32. M. Beltrán Lloris, "Notas arqueológicas sobre Gallur y la comarca de las Cinco Villas de Aragón”, en Caesaraugusta, vols. 33-34, 1969-70, 89-117.

33. F. Beltrán, "An irrigation decree from Roman Spain: the Lex riui Hiberiensis", Journal of Roman Studies, vol. 96, 2006, 147-197.

34. Puede verse una panorámica general en M. Á. Magallón, "Le monde rural à l'époque romaine dans la moyenne vallée de l' Ebre (Espagne)", en F. Réchin (Ed.), Nouveaux regards sur les uillae d'Aquitaine, Pau 2006, 308-324, cit. pp. 311, 312, 319, en la que se destaca la falta de estudios de detalle sobre la comarca de Zaragoza, ya subrayada por otros autores (E. Ariño, Catastros romanos en el convento jurídico cesaraugustano. La región aragonesa, Zaragoza, 1990, pp. 43-92, espec. pp. 88-92), con la impresión de que el poblamiento rural se hizo más denso a partir del siglo I a. E. y sobre todo en los siglos I-II d. E. Esta es la cronología que se desprende de áreas bien estudiadas como el territorio de Turiaso (Tarazona), en la ribera del río Queiles (J. Á. García y J. Pérez, "El poblamiento rural romano en el área de influencia del Municipium Turiaso. Patrones de asentamiento en torno al río Queiles, término municipal de Novallas”, en Turiaso, vol. 20, 2010 
como se ha dicho, contaban con raíces culturales diversas — vascones, iberos y celtíberos-, si bien entre ellos debían existir también gentes de procedencia itálica —como las asentadas en su momento en La Cabañeta- y probablemente grupos de ciudadanos romanos como los descendientes de los mencionados integrantes de la Turma Salluitana, galardonados con la ciudadanía romana en 89 a. E., si es que regresaron a sus hogares, sin descartar que pudieran haberse asentado en la zona emigrantes itálicos como los que menciona César a propósito de la batalla de Ilerda del año 49 a. E., entre los que se contaban romanos de toda condición ${ }^{35}$. Aunque no disponemos de información exacta sobre el grado de integración cultural de la población indígena en esta zona, sí existen datos para las áreas situadas ligeramente más al este, que, desde comienzos del siglo I a. E., proporcionan testimonios consistentes, por ejemplo, del uso del latín tanto por poblaciones itálicas, caso del letrero sobre pavimento musivo correspondiente a un collegium de La Cabañeta ${ }^{36}$, cuanto por indígenas, caso de los sellos bilingües sobre mortero procedentes de un alfar de localización indeterminada - hallados en La Corona y en La Caridad de Caminreal-, si son producto en efecto de un ibero romani$z^{2} a_{0}^{37}, y$, más significativamente aún, por ser documentos oficiales, de las leyendas bilingües de las cecas de Kelse y Usekerte, las más tempranas de la región, acuñadas hacia los años 40 a. E. ${ }^{38}$ No disponemos de información precisa sobre la situación más al oeste: no obstante en

2011, 55-95, cit. p. 94), en donde se ha puesto de manifiesto una tupida red de pequeños asentamientos rurales de tipo familiar que parece conformarse sobre todo en I d. E. En el territorio cesaraugustano las centuriaciones ligadas a la fundación de la colonia (estudiadas por Ariño, op. cit., 1990) y la construcción de las presas de Muel y Almonacid de la Cuba, de las que luego se hablará, en época de Augusto o Tiberio, junto con el estado de paz propio del período altoimperial justificarían el incremento en la densidad del poblamiento rural a partir del siglo I d. E., si bien infraestructuras hidráulicas como la mencionada en la Tabula Contrebiensis (ver nota 4), del año 87 a. E., sugieren la posibilidad de que en ciertas zonas la implantación rural fuera más temprana.

35. Caes. BC 1.51; sobre la interpretación de este pasaje, F. Beltrán, “Galos en Hispania”, Acta Archaeologica Academiae Scientiarum Hungaricae, vol. 57, 2006, 183-199, cit. pp. 195-196.

36. AE 2001, 1237; A. Ferreruela et alii, "Una inscripción republicana de la sede de una posible corporación en La Cabañeta (El Burgo de Ebro, Zaragoza)”, en AEspA, n 76, 2003, 217-230; F. Beltrán, “Firmas de artesano o sedes de asociaciones comerciales? A propósito de los epígrafes musivos de Caminreal (E.7.1), Andelo (K.28.1) y El Burgo de Ebro (HEp 11, 2001, 621 = AE 2001, 1237)” en E. Luján y J. M. García Alonso (Eds.), A Greek man in the Iberian street. Papers in Linguistics and Epigraphy in honour of Javier de Hoz. Innsbrucker Beiträge zur Sprachwissenschaft 140, Institut fur Sprachwissenschaft der Universität Innsbruck, Innsbruck 2011, 139-147 y próximamente, F. Beltrán, “Sedes colegiales indígenas de fecha republicana en Caminreal y Andelo?”, en O. Rodríguez (Ed.), Los espacios de reunión de las asociaciones romanas. Diálogos desde la arqueología y la historia, en homenaje a Bertrand Goffaux, en prensa.

37. Sobre estos rótulos, véase M. Beltrán, "Los morteros 'bilingües’ del valle del Ebro”, en Palaeohispanica, n 3, 2003, 59-71 y, en último lugar, M. J. Estarán, “Las estampillas ibérico-latinas K.5.4”, en Palaeohispanica, $\mathrm{n}^{\circ} 12,2012,73-90$.

38. Sobre las acuñaciones bilingües de la Hispania Citerior, F. Beltrán y M. J. Estarán, “Comunicación epigráfica e inscripciones bilingües en la Península Ibérica”, en C. Ruiz Darasse y E. Luján (Eds.), Contacts lingüistiques dans l' Occident méditerranéen antique. Collection de la Casa de Velázquez, 126, Madrid, 2011, 9-25, cit. p. 17. 
ciudades como Salduie y Contrebia Belaisca el impacto de las formas de vida romanas debía ser también apreciable como se observa, por ejemplo, en la arquitectura doméstica de corte itálico ${ }^{39}$, en la incorporación de tipos epigráficos monumentales típicamente romanos como los epígrafes sobre bronce contrebienses, o en la puesta en marcha de las infraestructuras hidráulicas saluyenses mencionadas por la tabula Contrebiensis del año 87 a. E., fruto sin duda de la incorporación temprana de técnicas de ingeniería romana ${ }^{40}$.

La delimitación del territorio asignado a Caesar Augusta dentro de esta comarca - que pudo ser tanto adquirido como confiscado- sólo recientemente ha podido ser establecido con una cierta seguridad ${ }^{41}$, gracias sobre todo al hallazgo de la Lex riui Hiberiensis que puso de relieve su extensión hasta más allá de Gallur, sede del pagus Gallorum, a más de $40 \mathrm{~km}$ al oeste de Zaragoza ${ }^{42}$, en donde hay indicios del asentamiento de veteranos legionarios pertenecientes seguramente al contingente fundacional y de origen probablemente galo ${ }^{43}$. La existencia de tres centuriaciones entre Caesar Augusta y el pagus Gallorum de fecha temprana, datadas en época de Augusto y Tiberio ${ }^{44}$, justamente en las zonas afectadas por el canal mencionado en la tabula Contrebiensis y por el riuus Hiberiensis del bronce de Agón, parecen confirmar que Alaun - fuera cual fuera su situación en esta época-y su territorio fueron incorporadas a la pertica cesaraugustana ${ }^{45}$, de suerte que en esta zona la colonia no sólo heredó el territorio saluyense, sino que incorporó también el alavonense, convirtiéndose en fronterizo con el de Cascantum — cuyo núcleo urbano se encuentra a más de $80 \mathrm{~km}$ de Zaragoza- a la altura de Belsino (Mallén), a unos $60 \mathrm{~km}$ al oeste de Zaragoza ${ }^{46}$.

Por el sur, el indicio más consistente lo ofrece la notable presa de Muel, de datación augústea, en cuya fábrica se han localizado grafitos de interpretación discutida ${ }^{47}$, y cuya única función pudo ser dar servicio a Caesar Augusta o a los agricultores que cultivaban las riberas de la Huerva hasta el núcleo urbano de la colonia, situado a menos de $30 \mathrm{~km}$. Ello implica la absorción del más septentrional territorio de Contrebia Belaisca, transformada a partir de este momento en un uicus $^{48}$, sin descartar que el territorio colonial pudiera llegar por el sur

39. Ver más arriba notas 28 y 31.

40. Al respecto, Beltrán, op. cit., 2009, 33-42 y F. Beltrán, “El agua y las relaciones intercomunitarias en la Tarraconense”, en Lagóstena, Cañizar y Pons, op. cit., 2010, 21-40, cit. pp. 27-31.

41. Beltrán y Magallón, op. cit., 2007, 97-103; Beltrán, op. cit., 2009, 59-60 y especialmente F. Beltrán, “El territorium Caesaraugustanum”, en I. Aguilera y J. L. Ona (Eds.), Delimitación comarcal de Zaragoza. Territorio 36, Zaragoza, 2011, 83-101.

42. Beltrán op. cit., 2006, 197-198.

43. Beltrán op. cit., 2006, 197-198 e ID., op. cit., 2009, 62-64.

44. Ariño op. cit., 1990, 43-92; Beltrán y Magallón, op. cit., 2007, 102-103.

45. En este sentido ya Ariño, op. cit., 1990, 92.

46. Beltrán op. cit., 2006, 161-162.

47. Inicialmente el equipo que estudia la presa los atribuyó a la legio IIII Macedonica: Uribe et alii, 2010 (vid. nota 21), 333-345 y P. Uribe, M. Á. Magallón y J. Fanlo, "New Evidence on Roman Water Supply in the Ebro Valley: the Roman dam of Muel (Zaragoza, Spain)”, en M. Zuchowska (Ed.), The archaeology of water supply, Oxford 2012, 75-83; recientemente, sin embargo, están cuestionando esta interpretación.

48. Activo hasta el siglo III d. E., al menos así lo creen Villar et alii, op. cit., 2001, 33-34. 
hasta el Campo de Cariñena, a poco más de $40 \mathrm{~km}$ de Zaragoza, en el que no se ha localizado hasta la fecha ningún asentamiento de rango urbano ${ }^{49}$. Más al este, también las tierras del Campo de Belchite, a unos $50 \mathrm{~km}$ del núcleo colonial, servidas por la enorme presa de Almonacid de la Cuba construida también en los inicios del principado ${ }^{50}$, debieron pertenecer al territorio cesaraugustano, pues no existe en la zona ningún asentamiento urbano al que pudiera dar servicio tan imponente infraestructura o que pudiera financiarla ${ }^{51}$. De hecho, la consistencia de esta propuesta viene avalada por la pertenencia de Belchite hasta la conquista cristiana (1118) al territorio de Saraqosta, su sucesora islámica ${ }^{52}$, que, por el este, llegaba hasta Quinto de Ebro, a casi $50 \mathrm{~km}$ de Zaragoza, indicio quizá de que, en este punto, se encontraba el límite con Celsa y que supondría la absorción también de los antiguos núcleos de La Cabañeta y La Corona.

Por el norte los indicios son más inciertos, aunque seguramente el territorio colonial alcanzaba la Sierra de Alcubierre, Zuera, en el valle del Gállego — como en época islámica一, y los Montes de Castejón, que marcarían las fronteras con Osca y Segia ${ }^{53}$.

\section{Colonos e incolae}

Según esta delimitación, hipotética desde luego, el territorio de la nueva colonia se extendía a lo largo de dos ejes que, desde Gallur a Quinto de Ebro y desde Zuera hasta Muel o Cariñena, alcanzaban en torno a $90 \mathrm{~km}$ de oeste a este y entre 60 y $75 \mathrm{~km}$ de norte a sur, y abarcaban, al menos, los antiguos solares de varias ciudades previas, entre las que cabe individualizar al menos Salduie, Alaun, Contrebia Belaisca, Los Castellazos, La Cabañeta y La Corona. Este hecho explica tanto que la colonia no llevara en su nombre referencia alguna a ninguna comunidad previa, pues en realidad su territorio estaba constituido no por el de una ciudad sino por los de varias ciudades preexistentes, cuanto el pasaje estraboniano que caracteriza la colonia como sunkismenai, término de interpretación discutida que podría aludir a su condición mixta ${ }^{54}$.

49. Asensio, op. cit., 1997, 132-133.

50. M. Beltrán Lloris y J. Viladés, “Aquae Romanae. Arqueología de la presa de Almonacid de la Cuba (Zaragoza)", Museo de Zaragoza, no 13, 1994, 127-193, datan la construcción en época de Augusto o Tiberio.

51. El yacimiento de Nuestra Señora de la Alegría no alcanza rango urbano, Asensio, op. cit., 1997, 327 ss.; Celsa se encuentra en la ribera contraria del Ebro y difícilmente pudo realizar las labores de mantenimiento atestiguadas en la presa hasta comienzos del siglo II d. E. (M. Beltrán y Viladés, op. cit., 1994, 192-193), habida cuenta del abandono del núcleo urbano comprobado a partir de c. 70 d. E. (M. Beltrán, op. cit., 1991, 25-27.

52. Sobre el territorio zaragozano en época musulmana: J. A. Souto, "El poblamiento del término de Zaragoza (siglos VIII-X): los datos de las fuentes geográficas e históricas”, en Anaquel de estudios árabes, no 3, 1992, 113-152.

53. Véase en detalle Beltrán, op. cit., 201.

54. Strab. 3.2.15; al respecto J. Arce, Caesaraugusta, ciudad romana, Zaragoza, 1979 que considera este término como una referencia a la condición mixta de la población de la colonia y Beltrán, op. cit., 2007, 101, 
Tales dimensiones podrían parecer desmesuradas si no tuviéramos constancia de otras colonias augústeas, con funciones similares, que fueron dotadas igualmente de grandes superficies como es el caso, particularmente, de Emerita Augusta, ${ }^{55}$ a cuya pertica se han llegado a atribuir ejes máximos de c. 90 por $200 \mathrm{~km} .{ }^{56}$

Independientemente de cuál fuera el estado de los núcleos urbanos más arriba mencionados y de sus correspondientes comunidades —en unos casos, como se ha dicho, abandonados desde décadas atrás y en otros quizá en plena actividad—, el resultado de la fundación colonial fue que, junto a los veteranos de las legiones IV, VI y X instalados por Augusto y quizás otros ciudadanos romanos que se sumaran al número inicial de colonos, la nueva comunidad hubo de gestionar el tratamiento de un crecido número de pobladores previos, entre los cuales, como se ha dicho, hay que contar grupos de peregrinos con diferentes raíces culturales -iberos, celtíberos, vascones-, pero también, probablemente, pequeños núcleos de ciudadanos romanos. Éstos, con toda seguridad, debieron ser incluidos entre los nuevos colonos y obtener sus correspondientes lotes. En cuanto a los pobladores de condición peregrina se abrían para ellos dos posibles opciones: expulsarlos o bien permitir que continuaran habitando en la nueva comunidad. Aunque no disponemos de noticias específicas al respecto, este segundo caso parece el más probable, pues, habida cuenta de la notable extensión del territorio colonial, la necesidad de mano de obra para cultivar las tierras haría conveniente la permanencia de la población previa o, al menos, de una parte de ella, pues es poco probable que el contingente de veteranos asentados - en torno a tres mil, como se ha visto- pudiera hacer frente a la explotación de tan amplio territorio. Del mismo modo la integración de la población local —independientemente de que hubiera podido recibir una compensación por sus tierras o de que les fueran expropiadas-, plantearía menos tensiones políticas que su expulsión forzosa, para la que, además, no había razones bélicas ni de otra índole, tratándose de áreas pacificadas desde antiguo y con un grado apreciable de asimilación de las formas de vida romanas. De hecho, la integración de la población peregrina en las colonias, pese a haber sido un tanto subestimada por la investigación, parece haber sido más habitual de lo que se venía considerando ${ }^{57}$.

ID., op. cit., 2009, 62, con una explicación alternativa, compatible con la anterior, que comportaría también una referencia a la constitución de la colonia sobre los territorios de varias ciudades preexistentes.

55. Véase la síntesis de P. D. Sánchez Barrero, “El territorio”, en X. Dupré (Ed.), Mérida. Colonia Augusta Emerita, L' Erma di Bretschneider, Roma 2004, 101-111 y, en particular, T. Cordero, "Una nueva propuesta sobre los límites del ager Emeritensis durante el Imperio Romano y la Antigüedad tardía”, en Zephyrus, 65, 2010, 149-165, con amplia bibliografía y detallado estado de la cuestión. Así queda de manifiesto en las observaciones del gromático Frontino, indicando que debido a sus dimensiones ni siquiera con tres adsignationes sucesivas, iniciadas, por cierto, en los extremos del territorio, pudo repartirse toda la tierra -Front. contr. agr. 51-52 (Lachmann) = Agen. Vrbic. contr. agr. 83-84 (Lachmann) - o en el tamaño de las centurias que, según Higino, alcanzaron el enorme tamaño de 400 iugera - Hygin. limit. const. 10-171 (Lachmann)-.

56. Cordero, op. cit., 2010, específicamente el mapa en fig. 13, 160; las distancias se han calculado entre Badajoz y Castilblanco, de oeste a este, y entre Puebla de Obando y Ribera del Fresno, de norte a sur.

57. Al respecto véase especialmente L. Gagliardi, Mobilità e integrazione delle persone nei centri cittadini romani. Aspetti giuridici. I, Milano, 2006, en donde se subraya la existencia de dos grupos diferenciados de 
En el caso de no ser expulsados, el tratamiento de la población local pudo adoptar varias modalidades ${ }^{58}$. Una posibilidad es que mantuvieran sus propias estructuras políticas según el esquema de las llamadas Doppelgemeinden o bien que fueran colocados en una situación de dependencia de la colonia como adtributi, ${ }^{59}$ si bien no existe indicio alguno de que éste fuera el caso en Caesar Augusta. Otra, más verosímil, es que fueran integrados como incolae y que se les asignaran lotes de tierra en la pertica ${ }^{60}$, seguramente los de menor calidad, como ocurrió, por ejemplo, con los Tricastini en la colonia de Arausio (Orange), según registra su catastro: (iugera) Tricastinis reddita, (agri) Tricastinis redditi ${ }^{61}$. En este caso, los pobladores previos, convertidos en incolae y, verosímilmente, reasentados en nuevas tierras, estarían sujetos a la exacción de tributos por parte de los magistrados urbanos así como a los munera possessionis y personalia, a cambio de los cuales podrían disfrutar de los servicios ofrecidos por la colonia, aunque obviamente sin plenos derechos políticos ${ }^{62}$, pues en la práctica eran considerados como residentes no ciudadanos de la colonia ${ }^{63}$. Sin embargo, finalmente, no puede descartarse tampoco la posibilidad de que una parte de los habitantes indígenas del territorio fueran incluidos en el número de colonos, como pudo ocurrir, por ejemplo, en Carthago y Ara Agrippinensium, si en estos términos pueden interpretarse ciertos pasajes de Apiano y Tácito ${ }^{64}$, o bien en colonias «titulares» como las hispanas de Tarraco y Carthago Noua ${ }^{65}$.

En cualquier caso, la desestructuración dominante entre las comunidades locales de la región a fines del siglo I a. E. no debe considerarse como un factor necesariamente ne-

incolae en las comunidades romanas, indigeni y trasferiti, los primeros particularmente frecuentes en las colonias romanas.

58. Una síntesis en Gagliardi, op. cit., 2006, 508 ss.

59. Gagliardi, op. cit., 2006, 174 ss., 214 ss.

60. Una situación recurrentemente registrada por los gromáticos Sicc. Flacc. cond. agr. 155, 6 ss. (Lach.); Hyg. cond. agr. 116, 16 ss. (Lach.); Gagliardi, op. cit., 2006, 20 y espec. 191-208 con el análisis de diversos casos.

61. AE 1962, 143, particularmente en el catastro B; Gagliardi, op. cit., 2006, 191-195.

62. Como se desprende de la Lex Malacitana $\$ 53$ sólo podían votar en las elecciones a magistrados $-\mathrm{y}$ agrupados en una sola curia- aquellos incolae, qui ciues $R$ (omani) Latiniue ciues erunt.

63. Sobre los aspectos fiscales relativos a los incolae, Gagliardi, op. cit., 2006, 224 ss.

64. App. Pun. 136; Tac. Hist. 4.28 (quod gens Germanicae originis eiurata patria [Romanorum nomen] Agrippinenses uocarentur); Gagliardi, op. cit., 2006, 201-211, especialmente 210, n. 184 y 211 n. 190; este procedimiento contaba con precedentes antiguos como el de Antium (Liv. 8.14).

65. La condición de colonia titular u honorífica de Tarraco, es decir de fundación carente de una deducción de veteranos en sentido estricto, aceptada generalmente desde trabajos como el de F. Vittinghoff, Römische Kolonisation und Bürgerrechtspolitik unter Caesar und Augustus, Franz Steiner Verlag, Wiesbaden 1952, 27 = 1243 n. 4, ha sido cuestionada recientemente por J. Ruiz de Arbulo, "La fundación de la colonia Tarraco y los estandartes de César", en J. L. Jiménez y A. Ribera (Eds.), Valencia y las primeras ciudades romanas de Hispania, Ajuntament de Valencia, Valencia 2002, 137-156, cit. p. 146; una propuesta que ha sido recibida con cautela por algunos, como I. Arrayás, "Tarraco, colonia romana", en Habis 36, 2005, 159 178, especialmente 177, pero aceptada, por ejemplo, por G. Alföldy, CIL II2/14, p. XCVI: "Colonia haud dubie deductione veteranorum constituta est". 
gativo para el establecimiento de la colonia, sino todo lo contrario, pues su integración en una colonia romana llamada a desempeñar un papel central en la región constituiría para muchos de ellos un aliciente: para los que disfrutaran de la ciudadanía romana - o pudieran acceder a ella con motivo de la fundación-, obviamente, pues implicaba integrarse en el número de colonos, mientras que para los peregrinos suponía incorporarse a una comunidad bien estructurada, en la que no disfrutarían de plenos derechos pero tendrían acceso a mejores servicios e infraestructuras. Por otra parte, desde la perspectiva del príncipe, la carencia en muchas comarcas del territorio de comunidades urbanas activas facilitaría la instalación de varios millares de nuevos pobladores militares, minimizando las tensiones con la población local.

\section{Los pobladores del territorio: tenues vestigios}

Desgraciadamente, apenas disponemos de información que refleje la presencia de población indígena en la colonia, dada la limitadísima conservación de inscripciones en las tierras aluviales del Ebro medio ${ }^{66}$. De hecho, no hay ningún epígrafe que exhiba una fórmula onomástica no romana con seguridad en el limitado registro cesaraugustano, salvo el grafito sobre sigilata de época augústea que recoge el posible nombre de raigambre céltica ${ }^{\star}$ Atullus, en el caso de que esté completo y no sea un simple [C]atullus latino, posibilidad que no puede en absoluto obviarse ${ }^{67}$. En lo que respecta a los epígrafes procedentes del territorio, en donde cabría esperar que esa población local se concentrara, cabe señalar el grafito, también sobre sigilata, procedente del uicus de Contrebia Belaisca que reza Let[ondonis ?], correspondiente a un nombre celtibérico ${ }^{68}$, mientras que no resulta clara la adscripción del nombre incompleto recogido en un titulus pictus procedente del uicus de Nuestra Señora del Pueyo de Belchite ${ }^{69}$.

Escasos también son los indicios sobre los veteranos en el territorio, aunque pueda mencionarse alguno sobre todo en el pagus Gallorum, en donde hay constancia de una fin-

66. Beltrán, op. cit., 2007, 3.

67. $A E 2000,771 c=\operatorname{HEp} 8$, 573. La existencia de un nombre celtibérico Atullus se apoyaría sobre todo en el nombre familiar atulikum comprobado en K.0.6 (J. Untermann, Monumenta linguarum Hispanicarum, IV, Ludwig Reichert Verlag, Wiesbaden 1997), explicable como un derivado del bien atestiguado nombre personal atu (K.22.2; K.1.3 I-34; D. Wodtko, Monumenta linguarum Hispanicarum, V, Wiesbaden 2000, 47-48); sin embargo la lectura de la tessera hospitalis en la que está grabado es exactamente atulnkum — no atulikum - y la pieza, de autenticidad sospechosa: F. Beltrán, C. Jordán e I. Simón: "Revisión y balance del corpus de téseras celtibéricas", en Palaeohispanica 9, 2009, 625-668, cit. pp. 629 y 654 núm. 12.

68. F. Beltrán, "Munic. Elaisio: sobre un nuevo municipio atestiguado en Botorrita (Zaragoza)", Novedades de epigrafía jurídica romana, Universidad de Navarra, Pamplona, 1989, 357-376, cit. p. 359 nota 10.

69. M. Beltrán, "Novedades de arqueología zaragozana”, en Caesaraugusta, vol. 41-42, 1977, 151-202, cit. pp. 171-173 y Arqueología 92, Zaragoza, 1992, 263-264; M. Mayer, "Las inscripciones pintadas en Hispania. Estado de la cuestión”, en H. Solin, O. Salomies y U. M. Liertz (Eds.), Acta colloquii epigraphici Latini Helsingiae 3-6 sept. 1991 habiti, Societas Scientiarum Fennica, Helsinki 1995, 79-92, cit. pp. 89-90: la lectura, insegura es Mâ+cus / [---]âecus. 
ca cuyo nombre fosilizaba seguramente el de su primer propietario, el centurión $\operatorname{Rectus}^{70}$, y otros datos que apuntan a la presencia de descendientes de los veteranos, de origen en gran medida galo, que integraban las legiones fundadoras de la ciudad ${ }^{71}$. Recuérdese que en el caso de Emerita la asignación de las tierras empezó por los extremos del territorio ${ }^{72}$, circunstancia que encajaría bien con estos testimonios procedentes del extremo occidental del territorio y con la construcción de la enorme presa de Almonacid de la Cuba en el sudeste de la pertica cesaraugustana.

\section{Epílogo: el crisol cesaraugustano}

Llegados a este punto sólo cabe recapitular. La fundación de Caesar Augusta supuso, desde luego, la creación de un centro vertebrador con proyección regional. Pero trajo consigo, además, una profunda recomposición no sólo del vasto territorio que Augusto le atribuyó para dotarle de una base económica acorde con esa función integradora, sino también de la población que en él habitaba. Para ello el príncipe adquirió - o confiscó- las tierras de diversas ciudades de la comarca, que, en muchos casos, a fines del siglo I a. E. todavía no se habían recuperado del negativo impacto provocado en ellas por las guerras sertorianas; reestructuró, además, la comarca con importantes obras viarias e infraestructuras hidráulicas que facilitaron la irrigación de amplias extensiones de terreno; e integró, finalmente en la nueva comunidad colonial junto al núcleo duro de veteranos legionarios a poblaciones locales de diferentes tradiciones culturales y condición jurídica, fuera como ciudadanos fuera como íncolas, que, en cualquier caso, parecen haberse fundido rápidamente en ese crisol de romanidad que fue colonia Caesar Augusta.

70. Beltrán, op. cit., 2006, 173; LrH I.24.

71. Caso, por ejemplo, del Sextus Aninius Lupus atestiguado en la tessera paganica de Gallur; Beltrán op. cit., 2009, 63; ID., "La tésera pagánica de Gallur (Zaragoza)", en Epigraphica 72, 2010, 151-168 y, sobre este tipo de inscripciones, “Tesserae paganicae”, en L. Lamoine, Cl. Berrendoner y M. Cébeillac-Gervasoni (Eds.), La praxis municipale dans l' Occident romain, Presses universitaires Blaise Pascal, Clermont-Ferrant 2011, 187-212.

72. Front. contr. agr. 51-52 (Lachmann) = Agen. Vrbic. contr. agr. 83-84 (Lachmann). 